\title{
Comparing Career Awareness Opportunities Of Academically At-Risk And Non At-Risk Freshman Engineering Students
}

Jeremy V. Ernst, Virginia Tech, USA

Bradley Bowen, North Dakota State University, USA

\begin{abstract}
This study explored how freshman engineering students utilized career awareness developmental opportunities prior to entry into post-secondary academics. Specifically, the study delved into separations and distinctions among students at-risk of non-continuation due to matriculation concerns and students non at-risk. Founded on the amended arrangement of Nasta's (2007) Career Exploration Survey-Revised instrument, singular factors were studied through hypotheses targeting career awareness behaviors among at-risk and non at-risk subgroups. The results show there are possible contradictions to commonly accepted beliefs about career awareness between at-risk and non at-risk students. Several deductions, considerations, and implications are highlighted based upon the findings of the study.
\end{abstract}

Keywords: At-risk; Freshman Engineering; Career Awareness

\section{INTRODUCTION}

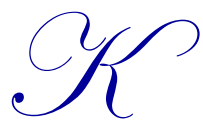

rumboltz theory characterizes individuals' inherited attributes, environmental conditions, learning experiences, and task skills as principal varieties of influence on career decision-making (Pryor, 2007). Pryor further describes that within this mode of career awareness and development theory, these influences interact producing self-observation generalizations, specific skillsets, and career-relevant behaviors as outcomes. Career awareness upon post-secondary academic entry is an important factor in professional goal setting and associated aspirations. Super (1957) contends that accurate professional framing stems from developmental opportunities and an overall sense of awareness (as cited in Sadeghi et. al, 2012). Further, Sadeghi et.al, report a common strand within career development frameworks, highlighting the late adolescence focal developmental stage (15-17 years of age). Buff and O'Connor (2012) identify that actual career awareness can be accessed in late adolescence and early adulthood in multiple forms, spanning formal and informal environments. Among these developmental interactions/experiences are coursework, internships, career counseling, professional mentoring, etc. The importance of involvement in such activities is apparent, however, degree of access and actual involvement in these experiences among late adolescent youth is unclear.

It is broadly assumed that prior to pursuit of a degree in engineering, there is an existent operational level of awareness associated with career prospects, specific disciplinary focus, and a base knowledge of academic expectations such as coursework and achievement thresholds. However, it is just that, an assumption, leaving little research suggestive of actual experiences that constitute an awareness of operational knowledge of engineering as a profession and a preparatory course of study. The direct impetus for exploration of engineering career awareness is its prospect as a relevant variable surrounding the retention concerns of underclassmen in engineering. Many universities have identification means in place for engineering students at-risk of academic non-continuation (Dekker, 2009). Further, Dekker describes an identifiable subset of students considered at-risk of non-continuation presenting indicators in early college stages. A consistent academic concern, and common indicator leading to noncontinuation, is matriculation status (Howard-Hamilton \& Sina, 2001). This study focued on how distinct career 
awareness opportunities in late adolescence, mainly high school, affect personal factors that possibly determine their ability to remain enrolled in an engineering program. The research question for this study is as follows:

Do engineering students susceptible to non-continuation of degree due to matriculation concerns have exposure and/or opportunity for the establishment of academic and professional goals through career awareness experiences and information sources while in late adolescence?

\section{STUDENTS AT-RISK IN HIGHER EDUCATION}

The definition of students at-risk often embodies sundry elements coupled with educational failure and/or increased probability of school dropout. Exclusion of suitable framing and designation, the phrase students at-risk is suggestive of numerous conditions that can make appraisals and understanding difficult. In post-secondary education, a student can be classified as at-risk of non-continuation of degree based on existing knowledge, skillsets, motivation or academic abilities below those of their immediate peers (Maxwell, 1997). As Dekker (2009) describes, these indicators are present and identifiable in early post-secondary academic stages.

To adequately identify and analyze pertinent educational features influencing successes of early state engineering students, academic circumstance must be factored (Clark \& Ernst, 2013). The academically at-risk condition for students in engineering is one in which there are a multitude of variables in effect that span far beyond course achievement (Ernst \& Clark, 2012). Following this notion, a career awareness variable isolation study commenced with a focal question: Are there identifiable differences between secondary education career awareness behaviors of freshman engineering students categorized as at-risk of non-matriculation and non at-risk? For the purposes of this study, the definition of at-risk and non at-risk are placed in the context of the likelihood for a student to matriculate through an engineering program. This study uses a matriculation parameter determined to be a GPA of 3.0, as defined by Clark \& Ernst (2012) and Clark and Ernst (2013). Therefore, for the purpose of the current study, students with a GPA below 3.0 at the end of their freshman year are classified as at-risk. Students with a GPA of 3.0 or higher at the end of their freshman year are classified as non at-risk. Although many engineering students are in good academic standing, the minimum GPA requirement for continued enrollment in engineering programs at this university varies, but is less than a 3.0. Therefore, students may continue their enrollment in the program with less than a 3.0 GPA, however, this study is based on prior research that shows students with less than a 3.0 after their freshman year are less likely to matriculate. Investigational hypotheses were posed to target specific evaluation of career awareness behaviors among the at-risk and non at-risk subgroups. There were fifteen hypotheses explored:

Research Hypothesis 1: There are no identifiable differences between freshman engineering students categorized as at-risk and not at-risk of matriculation regarding the extent to which they experimented with different career activities in high school.

Research Hypothesis 2: There are no identifiable differences between freshman engineering students categorized as at-risk and not at-risk of matriculation regarding the extent to which they sought opportunities to demonstrate skills in high school.

Research Hypothesis 3: There are no identifiable differences between freshman engineering students categorized as at-risk and not at-risk of matriculation regarding the extent to which they tried specific work roles to see if they liked them in high school.

Research Hypothesis 4: There are no identifiable differences between freshman engineering students categorized as at-risk and not at-risk of matriculation regarding the extent to which they investigated career possibilities in high school.

Research Hypothesis 5: There are no identifiable differences between freshman engineering students categorized as at-risk and not at-risk of matriculation regarding the extent to which they attended career orientation programs in high school. 
Research Hypothesis 6: There are no identifiable differences between freshman engineering students categorized as at-risk and not at-risk of matriculation regarding the extent to which they obtained information on specific jobs in high school.

Research Hypothesis 7: There are no identifiable differences between freshman engineering students categorized as at-risk and not at-risk of matriculation regarding the extent to which they gathered information on job trends, salaries, and general job opportunities in high school.

Research Hypothesis 8: There are no identifiable differences between freshman engineering students categorized as at-risk and not at-risk of matriculation regarding the extent to which they sought information on specific areas of career interest in high school.

Research Hypothesis 9: There are no identifiable differences between freshman engineering students categorized as at-risk and not at-risk of matriculation regarding the extent to which they participated in internships, practicums, fieldwork, or volunteer opportunities in high school.

Research Hypothesis 10: There are no identifiable differences between freshman engineering students categorized as at-risk and not at-risk of matriculation regarding the extent to which they sought career advice from a teacher or academic advisor in high school.

Research Hypothesis 11: There are no identifiable differences between freshman engineering students categorized as at-risk and not at-risk of matriculation regarding the extent to which they conducted online searches to obtain career information in high school.

Research Hypothesis 12: There are no identifiable differences between freshman engineering students categorized as at-risk and not at-risk of matriculation regarding the extent to which they spoke with family, friends, or the community about career advice in high school.

Research Hypothesis 13: There are no identifiable differences between freshman engineering students categorized as at-risk and not at-risk of matriculation regarding the extent to which they gathered information regarding additional education or training needed for a career in high school.

Research Hypothesis 14: There are no identifiable differences between freshman engineering students categorized as at-risk and not at-risk of matriculation regarding the extent to which they took coursework related to a career of interest in high school.

Research Hypothesis 15: There are no identifiable differences between freshman engineering students categorized as at-risk and not at-risk of matriculation regarding the extent to which they took career tests to analyze and assess interests, abilities and/or values in high school.

\section{STUDY PARTICIPANTS}

The participants in this study included students at a University in the upper Midwest who were enrolled as freshmen in the College of Engineering (CoE) during the 2012-2013 academic year. Overall enrollment based on classifications determined by credit hour completion at the University, indicate engineering attrition patterns. Figure 1 shows the number of students enrolled in the CoE for each cohort year from fall 2010 through fall 2013. It is visually amplified that the number of seniors for the 2010 cohort is more than the number of juniors from that same cohort because this category includes students with greater than 89 completed credits. The 2010 line graph is inclusive of student numbers from cohorts prior to 2010 that have not fulfilled requirements for graduation, indicating delayed completion for factors unknown. The breakdown of the $201090+$ credit hours data point is composed of the following categorizations: Total seniors of 2010 cohort $=723 ; 90-120$ credits $=380 ; 121-150=$ $251 ; 151-200=80 ;$ and $200+=12$. The 2011 number of enrolled students dropped from 512 to 402 , the 2012 number dropped from 525 to 513 and the 2013 cohort began with 502 students enrolled. 


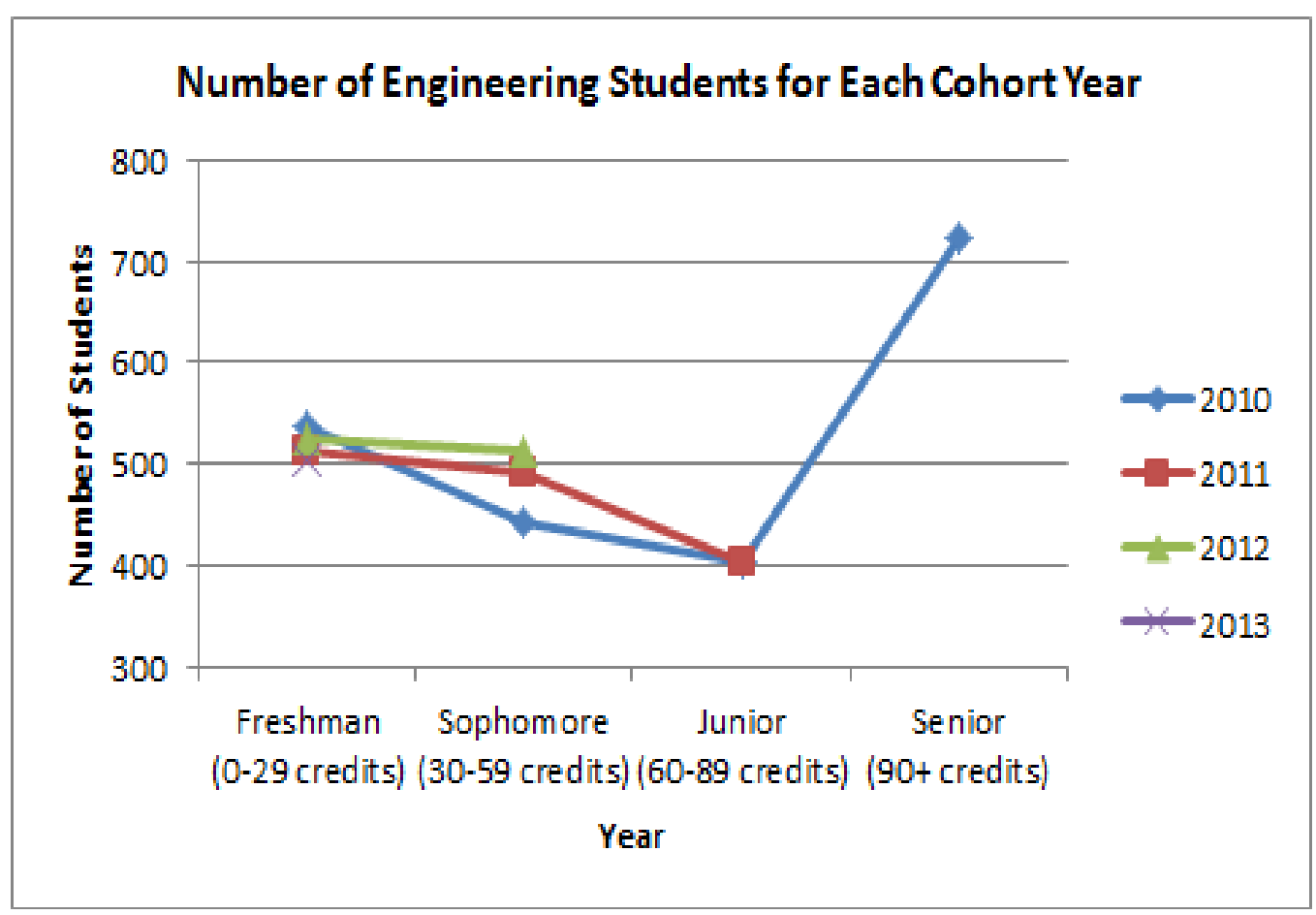

Figure 1. Total Enrollment In The College Of Engineering Based On Grade Level And Year As Of Fall Enrollment

To further describe the structure and enrollment patterns of the University CoE, enrollment in each of the six departments (Agriculture and Biosystems Engineering, Civil Engineering, Construction Management and Engineering, Electrical and Computer Engineering, Industrial and Manufacturing Engineering, and Mechanical Engineering) within the $\mathrm{CoE}$ is reported in Table 1 . In addition, the $\mathrm{CoE}$ has a general engineering curriculum for students who have not yet declared a major within the college. At the beginning of the 2013 academic year, there were a total of 525 students enrolled as freshmen in the CoE. At the beginning of the following academic year there were 513 sophomore students enrolled in the CoE. The breakdown of the number of students for each department is shown in Table 1. These numbers also include students who may have transferred from other universities as a sophomore as well as students transferring between departments in the CoE. The numbers for the sophomore year may increase due to students transferring between departments or students not obtaining the necessary credits to continue matriculating with the majority of the students in their cohort. The university identifies the different grade levels according to the number of credits obtained; freshman $=0-29$ credits, sophomore $=30-59$ credits, junior $=60$ 89 credits and senior $=90+$ credits. The numbers for departmental enrollment were obtained from the Student Support Center Director of the University CoE.

Table 1. Number Students Enrolled In Each Engineering Department

\begin{tabular}{lccc}
\hline Engineering Department & $\begin{array}{c}\text { Total Freshman Student } \\
\text { Enrollment Fall 2012 }\end{array}$ & $\begin{array}{c}\text { Total Sophomore Student } \\
\text { Enrollment Fall 2013 }\end{array}$ & $\begin{array}{c}\text { Non-General education } \\
\text { courses required 1st Yr. }\end{array}$ \\
\hline Agriculture and Biosystems & 22 & 21 & 3 \\
\hline Civil & 92 & 106 & 2 \\
\hline $\begin{array}{l}\text { Construction Management } \\
\text { and Engineering }\end{array}$ & 36 & 37 & 2 \\
\hline Electrical and Computer & 114 & 110 & 3 \\
\hline Industrial and Manufacturing & 34 & 27 & 2 \\
\hline Mechanical & 126 & 148 & 2 \\
\hline General & 101 & 64 & - \\
\hline
\end{tabular}


The coursework for the freshman engineering students consists mostly of courses that other freshmen would take. These courses may include mathematics, chemistry, college composition, public speaking or communications, as well as a one credit university skills and academic success course. In addition to these general courses, each engineering department requires two or three departmental specific courses during the freshman year. The number of non-general department specific courses required are also listed in Table 1. Therefore, by the end of their freshman year, each student in the CoE should have completed all the freshman general education courses as well as several departmental courses.

\section{INSTRUMENTATION}

This study employed an adapted survey to measure the career exploration behavior that participants demonstrated while in high school. The current instrument was modified from Career Exploration Survey-Revised (CES-R; Nasta, 2007). The CES-R measured "how much career exploration a person had done over the past three months" (Nasta, 2007, p. 17), consisting of 28 questions with interval Likert-scale of never, somewhat, a moderate amount, a substantial amount, and a great deal. CES-R was developed based on former work of Stumpf et al.; new career exploration methods of college populations were considered in CES-R. The current survey employed in this study selected 15 appropriate questions (\#1-8, 14, and 22-25) from the CES-R, and specifically asked students to recall their experience in high school in place of the past three months. The five-level Likert-scale was retained. Two more questions were added in order to test the eligibility of age and to distinguish students' academic standing (at-risk or non at-risk). The adapted survey contained 17 questions in total.

\section{METHODOLOGY}

To collect data for the project, the researchers obtained an email listing of all the students on the 2012-2013 freshman listserv from the Office of Registration and Records. To recruit students for the research project, an email was sent to each student on the listserv with a hyperlink to an electronic survey. The first page of the survey summarized the project and the purpose of the research, explained how participation in the research project by completing the survey was voluntary, and asked each willing participant to verify they were at least 18 years of age. The first survey was sent to this email list approximately two weeks before the beginning of classes the fall semester of 2013. A second email was sent out approximately four weeks later, two weeks after the beginning of the semester. The third and final email was sent approximately two weeks after the second email. After this final request, the researchers recorded the responses from the survey for data analysis. The Kruskal-Wallis one-way analysis of variance by ranks was employed to examine the medians of different independent samples. Due to the sampling methodology, parametric populations were not assumed. The Kruskal-Wallis one-way analysis of variance by ranks was designed to compare non-Gaussian populations (Ott, 2010; Sheskin, 2007).

\section{DATA ANALYSIS AND FINDINGS}

As identified in the discussion of the research question, investigational hypotheses were posed to target specific evaluation of career awareness behaviors among the at-risk and non at-risk subgroups. Fifteen individual hypotheses were evaluated using the Kruskal-Wallis Test. These are shown in Table 2. 
Table 2. Survey Items

\begin{tabular}{cc}
\hline Question $^{1}$ & Item \\
\hline & To what extent did you behave in the following ways in high school? \\
\hline 3 & Experimented with different career activities \\
\hline 4 & Sought opportunities to demonstrate skills \\
\hline 5 & Tried specific work roles just to see if I liked them \\
\hline 6 & Investigated career possibilities \\
\hline 7 & Went to various career orientation programs \\
\hline 9 & Obtained information on specific jobs or companies \\
\hline 10 & Gathered information on job trends, salaries, and general job opportunities in my career area \\
\hline 11 & Sought information on specific areas of career interest \\
\hline 12 & To what extent did you do the following in high school? \\
\hline 13 & Participated in an internship, practicum, fieldwork, or volunteer opportunity in a career field I am interested \\
\hline 15 & Sought career advice from a teacher or academic advisor \\
\hline 16 & Spoke to family, friends, or community about career advice \\
\hline 17 & Gathered information regarding additional education or training needed for your career \\
\hline Questions 1 and 2 asked for informed consent and self-reported GPA, respectively.
\end{tabular}

The results of the statistical analysis for all survey items are shown in Table 3 . Among these evaluations, four of the tabulated p-values for the test were determined to be smaller than 0.05 , therefore, the null hypotheses were rejected. The analysis of data suggests that the at-risk of non-matriculation sample group identified higher degrees of career awareness behaviors concomitant with trying specific work roles (Q5), investigating career possibilities (Q6), gathered information on job trends, salaries, and general job opportunities in my career area (Q9), and taking coursework related to a career of interest (Q16).

Table 3. Statistical Results

\begin{tabular}{|c|c|c|c|c|c|c|}
\hline Question & Group & $\mathbf{N}$ & Median & Ave. Rank & Chi Square & P-Value \\
\hline \multirow[t]{2}{*}{ Q } & At-Risk & 15 & 3 & 28.5 & 1.05 & 0.31 \\
\hline & Non At-Risk & 35 & 2 & 24.2 & & \\
\hline \multirow[b]{2}{*}{4} & At-Risk & 15 & 3 & 26.6 & 0.12 & 0.73 \\
\hline & Non At-Risk & 35 & 4 & 25.0 & & \\
\hline \multirow{2}{*}{5} & At-Risk & 15 & 3 & 31.3 & 4.74 & $0.03 *$ \\
\hline & Non At-Risk & 35 & 2 & 22.8 & & \\
\hline \multirow{2}{*}{6} & At-Risk & 15 & 4 & 31.3 & 3.99 & $0.05^{*}$ \\
\hline & Non At-Risk & 35 & 3 & 23.0 & & \\
\hline \multirow{2}{*}{7} & At-Risk & 15 & 3 & 30.8 & 3.33 & 0.07 \\
\hline & Non At-Risk & 35 & 2 & 21.2 & & \\
\hline \multirow{2}{*}{8} & At-Risk & 15 & 3 & 31.0 & 3.49 & 0.06 \\
\hline & Non At-Risk & 35 & 2 & 23.1 & & \\
\hline \multirow{2}{*}{9} & At-Risk & 15 & 3 & 32.8 & 5.99 & $0.01 *$ \\
\hline & Non At-Risk & 35 & 3 & 22.4 & & \\
\hline \multirow{2}{*}{10} & At-Risk & 15 & 4 & 29.0 & 1.33 & 0.25 \\
\hline & Non At-Risk & 35 & 3 & 24.0 & & \\
\hline \multirow{2}{*}{11} & At-Risk & 15 & 2 & 29.9 & 2.36 & 0.12 \\
\hline & Non At-Risk & 35 & 1 & 23.6 & & \\
\hline \multirow{2}{*}{12} & At-Risk & 12 & 2 & 23.6 & 0.21 & 0.64 \\
\hline & Non At-Risk & 34 & 2.5 & 25.6 & & \\
\hline \multirow{2}{*}{13} & At-Risk & 15 & 4 & 30.7 & 2.89 & 0.09 \\
\hline & Non At-Risk & 35 & 3 & 23.3 & & \\
\hline \multirow{2}{*}{14} & At-Risk & 15 & 3 & 24.3 & 0.16 & 0.69 \\
\hline & Non At-Risk & 34 & 4 & 26.0 & & \\
\hline \multirow{2}{*}{15} & At-Risk & 15 & 3 & 26.6 & 0.15 & 0.70 \\
\hline & Non At-Risk & 35 & 3 & 25.0 & & \\
\hline \multirow{2}{*}{16} & At-Risk & 15 & 4 & 32.0 & 4.64 & $0.03 *$ \\
\hline & Non At-Risk & 35 & 3 & 22.7 & & \\
\hline \multirow{2}{*}{17} & At-Risk & 15 & 3 & 25.7 & 0.01 & 0.93 \\
\hline & Non At-Risk & 35 & 3 & 25.4 & & \\
\hline
\end{tabular}




\section{DISCUSSION AND CONCLUSIONS}

This exploratory career awareness variable isolation study specifically investigated identifiable differences between secondary education career awareness behaviors of freshman engineering students categorized as at-risk of non-matriculation and non at-risk. Based on the adapted form or Nasta's (2007) CES-R instrument, individual factors were explored through independent hypotheses in targeting specific evaluation of career awareness behaviors among the at-risk and non at-risk subgroups. There are numerous conclusions, considerations, and implications based upon the study findings. First, career awareness as a central factor in non-continuation of degree, among subgroups within the participant sample, is largely dispelled. Overall, the utilization of career awareness information sources and experiences among the at-risk and non at-risk study subgroups were similar. There are four noted instances where the at-risk group reported higher utilization and exposure to career awareness opportunities: 1) work roles; 2) career possibilities; 3) company information; and 4) related coursework. This is suggestive of indicators and/or variables that have prospective influence on academic selection for certain identified subgroups, but are not outwardly relational to academic outcome. The research acknowledges that, overall, career awareness opportunities are important for high school students in choosing an intended college major. This study does not suggest that an increase in career awareness opportunities is a factor in determining a student's academic achievement. The results of this study show that career awareness opportunities may not contribute to a student's likelihood of matriculating through an engineering program while using student achievement as the parameter for defining at-risk and non atrisk students. Career awareness and exploration may possess dominant qualities concerning professional aspirations and degree pursuit within the participant sample, however, ultimate performance appears to not be a primary factor concerning investigated elements of career awareness.

Career awareness and career exploration "involves both cognitive and affective activities of interpreting and recreating past and present experiences and, moved by intrinsic or instrumental motives, of projecting them into the future. In addition, according to the processual view of the construct, self- and environment exploration are conceived as two dimensions of the same process rather than as two distinct exploratory processes (Taveira \& Moreno, 2003, p.190). Provided study evidence and following categorizations outlined by Taveira and Moreno, engagement in career-associated experiences relies much on intrinsic qualities and the existence of opportunities within given settings and less on actual ability and attainment. It is noted that departments of engineering in higher education have unique learner variables that lead to variance in attrition. Additionally, it is of mention that the current study relies on examination of general engineering without targeted exploration of concentrations within engineering. It is possible that study replication in alternate settings may produce varied results from those reported here.

\section{REFERENCES}

1. Buff, C.L \& O'Connor, S. (2012). Marketing career speed networking: A classroom event to foster career awareness. Marketing Education Review, 22(1), 72-82.

2. Clark, A.C. \& Ernst, J.V. (2013). Preferential learning of students in a post-secondary introductory engineering graphics course: A preliminary study focused on students at-risk. Published Proceedings of the American Society for Engineering Education Annual Conference and Exposition, Atlanta, GA, Session 6085.

3. Ernst, J.V. \& Clark, A.C. (2012). At-risk visual performance and motivation in introductory engineering design graphics. Published Proceedings of the American Society for Engineering Education Annual Conference and Exposition, San Antonio, TX, Session M209.

4. Clark, A.C. \& Ernst, J.V. (2012). A learner profile thematic review of introductory engineering design graphics students. Published Proceedings of the Engineering Design Graphics Division of the American Society of Engineering Education's $67^{\text {th }}$ Mid-Year Conference, Limerick Ireland, Session 3 p.106-110.

5. Dekker, G.W. (2009). Predicting students drop out: A case study. Eindhoven, The Netherlands: Eindhoven University of Technology.

6. Howard-Hamilton, M.F. and Sina, J.A. 2001. How college affects student athletes. New Directions in Student Services, 93(3): 35-45.

7. Ott, R. L. (2010). An Introduction to Statistical Methods and Data Analysis (6th ed.). Belmont, CA: Brooks/Cole, Cengage Learning. 
8. Pryor, R. G. L. (2007). Towards a composite theory of career development and choice. New South Wales, Australia: New South Wales Department of Industrial Relations.

9. Sadeghi, A., Baghban, I., Fatemeh, B., Ahmadi, A. \& Sadeghi, H. (2012). Career development trends of grades 8-12 Isfahanian students in Iran. Interdisciplinary Journal of Contemporary Research in Business, $4(2), 472-481$.

10. Sheskin, D. J. (2007), Handbook of parametric and nonparametric statistical procedures (4th ed.). Boca Raton, FL: Chapman \& Hall/CRC.

11. Maxwell, M. (1997). Improving student learning skills. Clearwater FL: HH Publishing, Inc.

12. Nasta, K. A. (2007). Influence of career self-efficacy beliefs on career exploration behaviors. Retrieved from

http://dspace.sunyconnect.suny.edu/bitstream/handle/1951/42318/KristenNastaMastersThesis.pdf?sequence $=1$

13. Taviera, M. D. C \& Moreno, M. L. R. (2003). Guidance theory and practice: The status of career exploration. British Journal of Guidance \& Counseling, 31(2), 189-207. 